\title{
LA PORNOGRAFÍA DE VENGANZA COMO VIOLENCIA DE GÉNERO EN EL DERECHO PENAL BRASILEÑO: LA CREACIÓN DEL TIPO PENAL POR LA LEY 13.718/18 Y LA APLICABILIDAD DE LA LEY
} $11.340 / 06$

\section{REVENGE PORN AS GENDER VIOLENCE IN BRAZILIAN CRIMINAL LAW: APPLICABILITY OF LAW № 11.340/06 AND LEGAL FRAMEWORK AS A CRIME AGAINST THE HONOR}

\section{VLÁDIA MARIA DE MOURA SOARES}

Doctora en Derecho por la Pontificia Universidad Católica de São Paulo. Profesora Adjunta da Facultad de Derecho de la UFMT.

JAMILLE CLARA ALVES ADAMCZYK Mestra en Derecho por la Universidad Federal de Mato Grosso - UFMT. Profesora Sustituta de la Facultad de Derecho de la UNEMAT.

\section{ANA CLARA MENDONÇA CATHALAT}

Miembro del grupo de investigación en la Universidad Federal de Mato Grosso UFMT.

\section{RESUMEN}

Objetivo: Se pretende alcanzar un estudio analítico de la pornografía de venganza, objetivando una mejor comprensión del fenómeno sociológico y del marco jurídico conferido al tema por el Derecho Penal brasileño, para que sea posible un enfrentamiento completo de la cuestión. El objeto será analizado exclusivamente por medio de un abordaje que toma la mujer como víctima. Es el objetivo de esta investigación verificar si se podría caracterizar dicha práctica como violencia de 
género y también si la pornografía de venganza podría ser adecuadamente tratada como un crimen contra la honra, como se ha estado tutelando esta conducta.

Metodología: La metodología es bibliográfica, sin el estudio del intercambio en el tratamiento de la derogación penal estudiada sobre el tema; el marco legal de la conducta como delito contra el honor; la elaboración de un tipo penal específico mediante la Ley ํo. 13.718/2018; y la posibilidad de aplicación de la Ley №. 11.340/2006 (Ley Maria da Penha).

Resultados: Después de toda la investigación, se constató que el fenómeno de la pornografía de venganza no puede ser considerado solamente como un crimen contra la honra, y su tratamiento como tal es inadecuado e insuficiente. Respecto al análisis de la aplicabilidad de la Ley Maria da Penha para casos de pornografía de venganza, verificase que los resultados fueron positivos en el sentido de ser posible la aplicación de esta ley para mayor protección de las mujeres víctimas de este crimen.

Contribuciones: La contribución del estudio está vinculada al diálogo entre sociología y derecho, así como a estimular una investigación en profundidad sobre la Ley Maria da Penha y su extensión.

PALABRAS-CLAVE: Pornografía de venganza; violencia de género; Ley Maria da Penha; Derechos fundamentales.

\section{ABSTRACT}

Objective: It is intended to reach an analytical study of revenge pornography, focusing a better understanding of the sociological phenomenon and the legal framework conferred to the subject by Brazilian Criminal Law, so that a complete confrontation of the issue is possible. The object will be analyzed exclusively through an approach that the woman is the victim. It is the objective of this investigation to verify whether such practice could be characterized as gender-based violence and also if revenge pornography could be adequately treated as a crime against honor, as this conduct has been protected.

Methodology: The methodology is bibliographic, without the study of the exchange in the treatment of the criminal repeal studied on the subject; the legal framework of conduct as a crime against honor; the elaboration of a specific criminal type through Law Nr. 13,718/2018; and the possibility of enforcement of Law no. 11,340/2006 (Maria da Penha Law).

Results: After all investigation, it was noted that the phenomenon of revenge pornography cannot be considered only as a crime against honor, and its treatment as such is inadequate and insufficient. Regarding the analysis of the applicability of Maria 
da Penha Law for cases of revenge pornography, the results were positive in the sense that it is possible to apply this law for greater protection of women victims of this crime.

Contributions: The contribution of the study is linked to the dialogue between sociology and law, as well as to stimulate an in-depth investigation into the Maria da Penha Law and its extension.

KEYWORDS: Revenge porn; gender violence; Maria da Penha Law; Fundamental rights.

\section{INTRODUCCIÓN}

La pornografía de venganza, o revenge porn en la lengua inglesa, es un fenómeno que se encuentra en expansión. Cada día son más frecuentes los casos en el que las consecuencias para las víctimas son profundamente negativas y, por veces, resultan en fatalidades.

En un análisis primario, es fácil llegar a la conclusión de que el incremento en el número de casos de pornografía de venganza se da por la propagación de nuevas tecnologías de la información. Sin embargo, la cuestión aquí tratada se profundiza mucho más allá de la mera exposición on-line.

En este estudio, el análisis trata del tema de la pornografía de venganza enfocándose en un recorte de género, buscando, además, tener una perspectiva sociológica y no sólo jurídica. El objeto será analizado exclusivamente por medio de un abordaje que toma la mujer como víctima, hecho que no excluye la posibilidad de un hombre figurar en esta condición, entretanto, dicho aspecto no será objeto de exposición. En este sentido, se cuestión: ¿es posible apuntar la pornografía de venganza como un modo de violencia de género? ¿Es razonable la aplicación de la Ley Maria da Penha en casos de pornografía de venganza? Considerando el marco legislativo anterior, hasta la Ley 13.718/2018, se cuestiona si el tratamiento otorgado por el ordenamiento jurídico es suficiente y adecuado para tutelar la revenge porn. 
Para estos fines, será utilizado la metodología de investigación bibliográfica, bajo una investigación cronológica, de modo a presentar la evolución del fenómeno investigado.

El tema del estudio es extremamente actual y exige una respuesta penal suficiente, ya que con el surgimiento de nuevos métodos, hubo una intensificación de la exposición de la sexualidad femenina, que siempre sufrió diversas restricciones, como modo de humillación y venganza por el comportamiento o rechazo demostrado por la mujer. Aunque las mujeres estén en constante evolución de derechos y oportunidades, todavía hay mucho que cambiar, puesto que la sexualidad femenina, hasta el momento es vista como un tabú o comportamiento inmoral, razón por la cual la pornografía de venganza debe ser considerada como una forma de violencia de género contemporánea.

\section{LA CUESTIÓN DE GÉNERO Y LA PORNOGRAFÍA DE VENGANZA}

La pornografía de venganza es el hecho de exponer públicamente cualquier material, fotos o videos, de desnudez o contenido sexual de una persona sin su autorización, en contexto cibernético ${ }^{1}$, generando una situación humillante y embarazosa para este individuo delante de la sociedad.

Es necesario diferenciar el uso de las expresiones pornografía de venganza y pornografía no consensual. Ambas se diferencian en el modo como ocurren y tal distinción es relevante para el Derecho Penal.

El término pornografía de venganza es utilizado en el contexto de un relacionamiento, en cualquier una de sus formas, entre quien divulga y la víctima (quien tiene su imagen divulgada), siendo esta última quien graba o consiente en la grabación de la imagen, y se la envía a su respectivo(a) parcero(a). Además, se sabe

\footnotetext{
${ }^{1}$ Algunos admiten que las orígenes de la pornografía de venganza surgió en tiempos anteriores a la propagación de la Internet, pero para los fines de este trabajo, se estudiará la pornografía de venganza como un fenómeno cibernético.
} 
que la pornografía de venganza tiene una motivación específica, como su nombre indica, de la venganza por medio de la humillación, causada por la exposición de la intimidad de aquel individuo. Aquí, por lo tanto, el agente recibe, o tiene acceso a la imagen de la víctima por su propia voluntad, que se origina de una relación de confianza, entretanto, posteriormente, esta imagen es divulgada con la intención de humillación o venganza.

Por otro lado, la difusión o divulgación no consentida de imágenes se trata de cualquier material de carácter sexual difundido sin el consentimiento de las personas retratadas. De este modo, no se hace distinción si hay un relacionamiento entre quien divulga y quien es la víctima, y tampoco se habla sobre motivaciones u objetivos de este acto, que pueden ser los más diversificados. Se destaca que la difusión no consentida abarca las más distintas modalidades de grabación y divulgación. De este modo, la pornografía de venganza es especie y aquella es género.

El objeto de este estudio es la pornografía de venganza, no alargándose en la difusión no consentida, puesto que esta tiene sus propias tendencias, siendo muy complejo proporcionar un recorte sociológico y jurídico tal cual pretende este trabajo.

La pornografía de venganza se subdivida en dos aspectos, siendo el primero más obvio y el segundo originario de una construcción. La tendencia más evidente en la pornografía de venganza es el contexto de un relacionamiento abusivo, en el cual una parte se aprovecha de la confianza de la otra, basado en una ventaja que tiene, que es el material de contenido sexual.

Sin embargo, tal ventaja no se limita a la posesión de fotos o videos íntimos, ya que se trata de una coyuntura histórica relacionada a la posición de cada individuo en la sociedad, de dominación versus sumisión, en este caso, entre hombre y mujer, respectivamente. Así, hay el segundo aspecto de la pornografía de venganza, que es el de que frecuentemente el hombre es el ofensor, quien difunde las fotos o videos, y la mujeres es la ofendida, quien tiene sus fotos o videos difundidos.

Esta situación proviene de la desigualdad de género, en la cual las mujeres figuran en situación desfavorable socialmente. De este modo, el tipo de divulgación del revenge porn es visto de forma distinta, dependiendo de la víctima. Hay una gran 
diferencia en el tratamiento de hombres y mujeres, el cual hace que la exposición femenina tenga una repercusión negativa. Frecuentemente se dice que la victima puso su confianza en alguien que no debería, sin hacer una buena elección de parcero y que probablemente la víctima era una mujer "poco respetable moralmente", haciendo un juicio respecto a la mujer ofendida. Así, además de tener su intimidad expuesta públicamente, la mujer es revictimizada cuando es juzgada socialmente y pasa a convivir con vergüenza y culpa.

Es posible visualizar que el problema de la divulgación no consentida de fotos o videos de desnudez no reside exclusivamente en el contenido sexual de este material, sino que se encuentra en la proyección de personas del género femenino, de las cuales se exige pudor y recato, bajo una perspectiva machista y patriarcal. La pornografía de venganza, por lo tanto, está íntimamente relacionada a la idea de género y al comportamiento social.

La comprensión de que las diferencias entre hombres y mujeres son de orden natural siempre se destacaron entre los que han intentado explicar las desigualdades entre lo masculino y femenino, sugiriendo que tales diferencias son irremediables e imposibles de ser superadas. En ciertos momentos, la explicación de la asimetría entre hombres y mujeres se fundamentaba en discursos divinos o religiosos (PERROT, 2007, p.80), dependiendo de credo e ideología específica, los cuales no pueden ser aceptados universalmente.

En el período moderno, estas tesis fueron revistas y fundamentadas predominantemente en las ciencias naturales, después de la llegada del empirismo (BEAUVOIR, 1970, p.25). La idea de que las desigualdades se basan en aspectos biológicos ganaron gran popularidad por el contexto histórico-social de glorificación de los estudios científicos y los nuevos descubrimientos. En las teorías de las ciencias de la naturaleza se buscó estudiar las diferencias entre hombres y mujeres bajo una perspectiva de su cuerpo y composición física, basándose en el sexo. Tales tesis utilizaban el sexo como elemento central de sus análisis, que se elaboraban bajo un punto de vista biológico en que se estudiaban órganos, hormonas, membranas, funciones, etc. 
En la actualidad, tales teorías se volvieron insuficientes para explicar las desigualdades entre hombres y mujeres, puesto que menosprecian el aspecto social en sus análisis ${ }^{2}$. No se dice que inexisten diferencias - fisiológicas, biológicas, hormonales, genéticas, físicas - entre hombres y mujeres, lo que se quiere demostrar es que ya no es adecuado afirmar que tales diferencias siguen a desarrollar papeles preponderantes en una sociedad extremamente compleja y organizada.

Tales teorías llegan hasta a un punto paradoxal: ¿Cómo aceptar que el biológico domine el social en todos sus aspectos, ya que tales contextos sociales e instituciones en general surgieron con la propia idea de sociedad? La sociedad compleja como es actualmente es incompatible con la idea de supremacía biológica, genética, del hombre en sí mismo.

No se puede comprender el cuerpo en sí mismo, como un elemento apartado del medio socia. Hay que observar el valor que el mismo recibe en la sociedad, por medio de simbologías y significados. Es con base en el lenguaje y, sobretodo, en los símbolos, que Joan Scott delimita el concepto de género (SCOTT, 1995, p.71-99), el cual representa una alternativa al pensamiento dual como modo de categorizar personas, cosas, conductas, fenómenos, actividades, profesiones, ocupaciones, etc.

Según Scott (1995, p.71-99), "el género es un elemento constitutivo de relaciones sociales basado en las diferencias percibidas entre los sexos". La idea de género determina que las distinciones fundamentadas en el binomio masculino y femenino son meramente de carácter social. Por lo tanto, el concepto de género pasa a ser utilizado como manera a referirse a la organización social de la relación entre los sexos (SCOTT, 1995, p.71-99).

\footnotetext{
2 En traducción libre: "El cuerpo no es una cosa, es una situación: es nuestra comprensión del mundo y el boceto de nuestros proyectos. La mujeres es más débil que el hombre; ella tiene menor fuerza muscular, menor número de glóbulos rojos, menos capacidad respiratoria; corre menos rápido, levanta menos peso, no hay ningún deporte en el cual pueda competir con él; ella no puede enfrentar el macho en la lucha. (...) En verdad, estos hechos no podrían ser negados, pero no tienen sentido en sí mismos. Desde que aceptamos una perspectiva humana, definiendo el cuerpo a partir de la existencia, la biología se vuelve una ciencia abstracta; en el momento en el cual el dado fisiológico (inferioridad muscular) asume un significado, esto surge desde pronto como dependiente de todo un contexto, la "debilidad" solo se revela como tal a la luz de los fines a los cuales el hombre se propone, de los instrumentos que dispone, de las leyes que se les impone" - BEAUVOIR, 1970, p. 54.
} 
En este contexto, desaparece la creencia de que las características físicas o psíquicas de la mujer sean anteriormente definidas en razón del sexo, o que existan limitaciones o predisposiciones naturales a cualquier comportamiento femenino.

El género es aprendido por cada individuo desde el nacimiento. En su obra "El Segundo Sexo" (BEAUVOIR, 1967, p.9), Simone de Beauvoir describe el proceso de construcción de estas identidades sociales ${ }^{3}$, diferenciando la creación de niñas y niños. Aquellas, desde muy temprano, aprenden sobre el recato, la pureza y la pasividad, mientras que estos son estimulados constantemente a ser el contrario de todo esto, así, se introduce la idea de virilidad, iniciativa, dominación, etc (BEAUVOIR, 1967, p.13).

Se percibe que tanto los hombres como las mujeres tienen su identidad construida socialmente. Entretanto, lo que ocurre con las mujeres es que estas se encuentran en posición desfavorable respecto a los hombres. Tales diferencias son determinadas desde la infancia. Los niños, desde muy temprano, son estimulados en su autonomía a imponerse a los otros y, en esto, también se definen para sí mismos (BEAUVOIR, 1967, p.22). Por otro lado, a las niñas "les enseñan que es necesario agradar, hacerse objeto; ella debe, por lo tanto, renunciar a su autonomía. Le tratan como una muñeca viva y le recusan la libertad" (BEAUVOIR, 1967, p.22), traducción libre.

De igual modo, y en el contexto de la pornografía de venganza, el juego sexual es marcado por ideales de género. Los hombres toman la iniciativa, son los responsables por todo el acto: sea en la fase de la conquista, sea en la fase sexual. Las mujeres, por otro lado, deben aguardar el emprendimiento masculino, sin enseñar su determinación o decisión.

El juicio que se hace a las mujeres que presentan comportamiento sexualmente activo es el gran ejemplo de la dominación masculina en la sexualidad femenina. El hombre es visto como el sujeto sexual, de modo que a la mujer se le

\footnotetext{
${ }^{3}$ Simone de Beauvoir determina conceptos de género, aunque haya utilizado el término "sexo". Como fue afirmado anteriormente, la noción de género como el concepto que se tiene en la actualidad surgió en el fin del siglo XX, mientras que la obra en cuestión fue publicada originalmente en 1949. Sin embargo, la obra de Beauvoir fue fundamental para los estudios de género posteriores.
} 
otorga un rol secundario. Caso la mujer renegué su papel y pase a ser sujeto, será ridiculizada por la sociedad, la cual atribuye la idea de acción al hombre, pero jamás a la mujer.

Es exactamente en este contexto en que la pornografía de venganza ocurre y este es el motivo por el cual la divulgación de la intimidad femenina es más nociva que la masculina.

En el caso del hombre, este recibe elogios, sea a su performance o a su órgano sexual (DUARTE, 2017), y se envanece con los comentarios, que no son hechos con el objetivo de despreciarlos. Raramente se hace comentarios cuanto a su moral, valores o estilo de vida. Si se les comenta algo indeseado, son frutos de chistes (EXTRA, 2016), los cuales difícilmente tienen el objetivo de atingir a la autoestima del hombre.

No se dice que los hombres no pueden sufrir con la exposición de imágenes íntimas. Los hombres también sienten su intimidad violada, y pueden sufrir las consecuencias de esto. Entretanto, se cuestiona: ¿Cuál es el potencial lesivo de esta conducta para un hombre? Frecuentemente las consecuencias para el sexo masculino no pasarían de chistes o leves reprensiones, que difícilmente se trata de un juicio moral o ético, relacionado a su honra. De este modo, en muy pocos casos hay una humillación tal cual se pasa en el caso de las mujeres. Con ellas, por otro lado, se critica la honra, la ética, la moral, la honestidad y, muchas veces, hasta su papel como madre o esposa (NOMURA, 2017, p.1).

En este contexto surge la violencia de género, cuyo concepto es toda violencia que ocurre en causa de conflictos generados por normativas de género. Esta violencia se fundamenta en elementos culturales (OLIVEIRA, 2010) y se pasa en el núcleo de la sociedad, que sistemáticamente reproduce los padrones impuestos.

La violencia de género es un mecanismo propio de la sociedad que ha demarcado normativas de género y que ha desarrollado medios de represión con el objetivo de mantener el orden establecido. De ahí, hay la idea de que la violencia de género generalmente tiene las mujeres como destinatarias, ya que estas figuran como las víctimas principales de tal fenómeno. 
Después de las explicaciones bajo la perspectiva sociológica, es necesario cuestionar lo que entiende el ordenamiento jurídico como violencia de género. La Declaración sobre la Eliminación de la Violencia Contra la Mujer de la Organización de las Naciones Unidas (1993) conceptúa violencia de género como:

(...) todo acto de violencia basado en la pertenencia al sexo femenino que tenga o pueda tener como resultado un daño o sufrimiento físico, sexual o sicológico para la mujer, así como las amenazas de tales actos, la coacción o la privación arbitraria de la libertad, tanto si se producen en la vida pública como en la vida privada.

El concepto de esta disposición se revela apurado puesto que utiliza el término "género" en lugar de "sexo", sin implicar en el binomio biológico hombre x mujer.

De igual modo, la Convención de Belém do Pará también conceptúa la violencia de género basándose en la idea de género, entendida como "cualquier acto o conducta basada en el género, que cause muerte, daño o sufrimiento físico, sexual o psicológico a la mujer, tanto en la esfera pública como en la esfera privada" (CIDH, 1994).

Por otro lado, hay la Ley 13.104/2015 que instituyó la cualificación del feminicidio para el crimen de homicidio. Esta legislación utiliza el concepto de sexo como marco para conceptuar la idea de violencia de género. Ya la Ley 11.340/2006, la Ley "Maria da Penha", relaciona la violencia de género con la violencia doméstica y familiar. Las especificaciones de la Ley Maria da Penha serán explicadas en el tópico 3 de esta investigación.

\section{LA PORNOGRAFÍA DE VENGANZA Y LA ALTERACIÓN DEL CÓDIGO PENAL}

Las Constituciones de los Estados aportan el conjunto de bienes, garantías y premisas consideradas las más importantes a determinados ordenamientos jurídicos. En esta concepción, la previsión constitucional de bien jurídico no se fundamenta solamente en las limitaciones del Estado respecto a derechos fundamentales pero 
también se basa en la posibilidad de que su actuación sea coercitiva de modo a proteger los bienes jurídicos, legitimando la intervención del Derecho Penal a los bienes tutelados en la Carta Magna

Según Feldens, "la Constitución constituye el cuadro referencial obligatorio - y no solamente sugestivo, considerando la superioridad normativa - de la actividad punitiva" (FELDENS, 2005, p.70), en traducción libre. La Constitución, en tanto que reguladora de la estructura del Estado, es el fundamento y el medio que asegura la eficacia y eficiencia de todo el sistema normativo, razón por la cual el autor se refiere a la jerarquía de las normas constitucionales, de las cuales el ordenamiento jurídico infra constitucional debe buscar su legitimidad. De esta manera, habrá correlación entre la Constitución y la norma penal, ya que esta deberá adecuarse a aquella. Feldens proclama que el "discurso sobre la legitimación del Derecho Penal es, antes de todo, el discurso sobre su adaptación material a la Constitución" (FELDENS, 2005, p.38), en traducción libre.

Lopes reafirma que la "Constitución y el Derecho Penal existen, ambos, como reservatorio de las libertades humanas, de modo que solamente un ajustado concierto entre ellos hace que sea posible la legitimación de una incriminación" (LOPES, 2000, p.175), en traducción libre.

La vinculación entre la Constitución y la actuación del Derecho Penal está relacionada a los mandatos constitucionales de criminalización ${ }^{4}$, que tienen como objetivo el enfrentamiento de determinadas conductas a fin de tutelar, penal y satisfactoriamente, bienes valiosos a la sociedad. El deber de prestación penal vinculado a la Constitución ${ }^{5}$ objetiva asociarse al sistema de bienes jurídicos constitucionales, pasando por la "necesidad de que la tutela penal este orientada

4 Denominados también como: cláusulas de criminalización, mandados constitucionales de penalización o obligaciones constitucionales de criminalización.

${ }^{5}$ De modo general, Feldens diferencia el mandado constitucional del mandado legal de criminalización. Aquel impone una obligación de legislar buscando la protección del bien jurídico penal, caracterizada como una obligación positiva, sin embargo, que no define la conducta criminosa, sirviendo como base constitucional para direccionar la tutela. Por otro lado, el mandado legal de criminalización vincula los ciudadanos que deben sujetarse a la ley, definiendo la conducta criminosa así como su respectiva sanción, lo que se caracteriza como una obligación negativa, en la cual el particular no debe practicar la descripción del tipo. 
solamente a los objetos legítimos hacia la necesidad de tutela penal en un determinado ámbito valorativo" (FELDENS, 2005, p.74), en traducción libre.

El legislador, por lo tanto, debe utilizar la Constitución como aspecto fundamental y legítimo de la tutela de los bienes que considera, llevando en consideración que ella demuestra un campo de actuación de intervención penal para ciertos derechos y valores considerados esenciales e irrenunciables. Además, la Constitución Federal debe servir de fundamento de todo el ordenamiento jurídico positivado.

No obstante la previsión y tutela constitucional de protección a determinados bienes jurídicos, las normas constitucionales, por su naturaleza, no tienen la prerrogativa de auto aplicación, razón por la cual el legislador ordinario utilizará la Constitución como referencial mínimo de tutela penal, así como deberá evaluar la necesidad de tipificación de determinada conducta.

La libertad es un derecho fundamental establecido por Constitución brasileña. Esta libertad no puede ser vista solamente en su ámbito genérico, de modo que es necesario que a este concepto se le incluya también la libertad sexual, que dice respecto al poder de elección de un individuo cuanto a quien relacionarse y como irá hacerlo. Cuando hay una violación a la libertad sexual, es violada también la libertad genérica, entretanto, en razón de sus particularidades, aquel bien jurídico merece protección específica.

La libertad sexual, entendida como aquella parte de la libertad que se refiere al ejercicio de la propia sexualidad y, de cierto modo, a la disposición del propio cuerpo, aparece como un bien jurídico merecedor de protección penal específica, no siendo suficiente para abarcar toda su dimensión la protección genérica concedida a la libertad general (CONDE, 2004, p.206). (traducción libre)

De este modo, el Estado no podrá presentar protección insuficiente a bienes jurídicos previstos por la Constitución, debiendo respetar los derechos fundamentales, no interfiriendo de manera excesiva (abstinencia - perspectiva negativa) en el ámbito del individuo violador de la norma, así como deberá ofrecer protección suficiente 
contra agresiones a bienes jurídicos (actuación - perspectiva positiva). Así, antes de la Ley 13.718/2018 era evidente el tratamiento deficiente del legislador al bien jurídico, sin acompañar las alteraciones cuanto al modo de ejecución de los crímenes. Con el adviento del cambio legislativo hubo taxatividad cuanto a la conducta de la pornografía de venganza y se otorgó mayor protección a las víctimas de este crimen, respetando la importancia del bien jurídico tutelado.

Antes de las alteraciones proporcionadas por la Ley 13.718 de 24 de septiembre de 2018, que incluyó el tipo penal en el artículo 218-C, párr. 1ํe en el Código Penal, inexistía tipificación específica para la pornografía de venganza, por el que era necesario analizar profundamente el bien jurídico ofendido a fin de determinar cual encuadramiento era el más adecuado.

Se ajustaba la revenge porn en el contexto de los crímenes contra la honra, con los tipos penales de injuria y difamación. Antes de la reciente legislación, esta era la tipificación más común de la conducta (VALENTE; RUIZ; BULGARELLI, 2016). Dichos tipos penales no ofrecían la protección más adecuada a los casos de revenge porn, confiriendo una tutela jurídica insuficiente e inadecuada a la gravedad de la conducta y a la importancia del bien jurídico que se debería proteger.

En situación similar al de la pornografía de venganza, hay la Ley 12.737/2012, que alteró el Código Penal al inserir el artículo 154-A en el ordenamiento. También conocida como Ley "Carolina Dieckman", después del crimen sufrido por la actriz Carolina Dieckman que tuvo sus fotos íntimas obtenidas mediante su notebook y difundidas on-line, el dispositivo en cuestión inserta el tipo de invasión de dispositivo informático al ordenamiento nacional y tiene por objetivo tutelar la seguridad informática y la integridad de informaciones en la red. Aunque esta ley signifique un avance en casos de divulgación no consentida y por veces la conducta que tipifica sea confundida con la pornografía de venganza, sus disposiciones no pueden ser aplicadas a casos de revenge porn, en los cuales la obtención de fotos o videos no se dio por la invasión de cualquier dispositivo, pero por la libre disposición de la víctima.

También hay mucha divergencia respecto a la posibilidad de la aplicación de la Ley Maria da Penha, así como de todo su sistema de protección. Este marco jurídico 
es el menos considerado en casos de pornografía de venganza puesto que había mucha discusión sobre la consideración de la pornografía de venganza como una forma de violencia de género.

A la reluctancia en considerar la revenge porn como violencia de género se sumaba el hecho de que la legislación nunca hizo cualquier mención a la violencia de género on-line, de modo que las situaciones mas frecuentes en las cuales se suscitaba la Ley Maria da Penha son los casos de violencia física o mismo los casos de violencia psicológica más directos, en los cuales la cuestión de género es más evidente.

La injuria y la difamación son tipos penales que integran el Capítulo $\mathrm{V}$ de la Parte Especial del Código Penal, y tienen la honra como bien jurídico tutelado. Antes de la Ley 13.718/2018, este era el tratamiento más común conferido por el Poder Judiciario para los que buscan ejercer su pretensión jurídica a través del Derecho Penal (VALENTE; RUIZ; BULGARELLI, 2016). Ocurre que tal tipificación noes adecuada para la pornografía de venganza, ya que el bien jurídico ofendido por esta conducta no es esencialmente la honra.

Hay que abordar los dos sentidos de la noción de honra, el subjetivo y el objetivo. La noción subjetiva se trata del sentimiento de estima, respetabilidad y dignidad que cada ser humano tiene por sí y lleva en consideración el conjunto de valores que cada persona lleva consigo. La noción objetiva de este concepto se trata de la reputación, del juicio de valor que es elaborado por la sociedad en relación a un individuo. La definición de honra solamente por el sentido objetivo o subjetivo sería insuficiente para conceptuar un derecho tan completo, por lo tanto, su concepto debe abarcar ambos ámbitos. En este sentido, apuntando la definición del derecho a la honra, afirman Mitidiero, Marinoni y Sarlet (2017, p.519), en traducción libre:

El derecho a la honra protege, en esta perspectiva, la reputación de la persona y la consideración de su integridad como ser humano por terceros y por el propio titular de derecho (honra subjetiva), destinándose a proteger el individuo de expresiones u otras formas de intervención en el derecho que puedan afectar el crédito y sentimiento de estima e inserción social de alguien. 
Actualmente hay gran cercanía entre el concepto de honra y el de dignidad de la persona humana, principio fundamental del ordenamiento jurídico brasileño, de modo que no se puede tratar de la dignidad de la persona humana sin que haya respeto a la honra. Así, la tutela de la honra abarca la mayoría de las áreas de estudio del Derecho, atingiendo, en mayor o menor grado, casi todas las situaciones jurídicas (ALMEIDA, 2015, p.17).

El crimen de difamación está previsto en el artículo 139 del Código Penal. Difamar significa descreditar públicamente a alguien (NUCCl, 2016, p.684), por lo tanto, el bien jurídico ofendido es necesariamente la honra objetiva o la reputación del individuo víctima de la ofensa.

Además de esto, la pornografía de venganza también es frecuentemente considerada en el ámbito del tipo de injuria (VALENTE; NERIS; RUIZ; BULGARELLI, 2016), previsto en el artículo 140 del Código Penal. Aunque también se trate de honra, en la injuria la honra es en su dimensión subjetiva es ofendida, de modo que se ofende la dignidad y respetabilidad que cada persona nutre por sí misma, el autoimagen.

No obstante la influencia de la honra ser unánime en el ordenamiento jurídico, hay diversos problemas en considerar la honra como el ponto central de la pornografía de venganza. Este tratamiento del tema es cuestionable por relacionar honra y comportamiento sexual, sobretodo por el hecho de que se trata de una conducta estrictamente relacionada a la cuestión de género y que victima predominantemente mujeres.

El problema interpretativo-simbólico (VALENTE; NERIS; KIRA, 2017) en afirmar que la cuestión de la pornografía de venganza está relacionada solamente con la honra reside en condicionar la reputación de un individuo al contenido sexual expuesto, lo que se traduce en el modo como este individuo concibe su propio cuerpo, sus prácticas, opciones y comportamiento. Considerando que las dos dimensiones de la honra están relacionadas entre sí, esta reputación repercutiría en el sentimiento de estima y dignidad que cada persona tiene por sí mismo, como si este sentimiento de respetabilidad propia estuviera vinculada al comportamiento sexual. 
Decir que la revenge porn es una cuestión esencialmente de honra sería afirmar que el problema reside en la reputación atingida por el carácter sexual de las fotos y que este ultimo seria naturalmente problemático. El problema de la pornografía de venganza, diferentemente de se tratar de una cuestión del contenido sexual, esta en el hecho de que la victima retratada no dispuso de su cuerpo como quiso. Simbólicamente, el individuo tiene su propio cuerpo alienado de sí mismo, cuando este es representado de forma no autorizada, en un contexto distinto de aquel que motivó su grabación en primer lugar. No hay respeto, por lo tanto, a la libertad que el individuo tiene de exponerse, o no, para quien, cuando y donde quiera. Por esto, la pornografía de venganza es mucho más una cuestión de libertad sexual que de honra.

Como las víctimas de la pornografía de venganza son en su mayoría mujeres, decir que la pornografía de venganza es una cuestión primordialmente de honra, y no de libertad sexual, es un retroceso. Como antes dicho, la mujer tiene su sexualidad reiteradamente negada en el contexto social. Entretanto, cuando expuesto, el comportamiento sexual femenino es el elemento principal formador de su reputación, respeto y estima dentro de la sociedad.

Después de un creciente numero de víctimas y un largo período sin protección específica en el Derecho Penal, en septiembre de 2018 entró en vigor la Ley 13.718 que altera disposiciones concernientes a crímenes contra la dignidad sexual, previstos en el Título VI del Código Penal brasileño. Esta ley, además de modificar tipos penales ya constantes en el Título VI, añadió al Código Penal los tipos de importunación sexual y difusión de imágenes de violación, de violación de vulnerable o de sexo, desnudez o pornografía sin el consentimiento de la víctima y modificó la especie de acción penal respecto a los crímenes sexuales para acción pública incondicionada.

Respecto a la pornografía de venganza, se analiza el tipo penal del artículo 218-C, con la siguiente redacción:

Difusión de imágenes de violación o de imágenes de violación de
vulnerable, imágenes de sexo o de pornografía. Artículo $218-C$. Ofrecer,
cambiar, disponer, transmitir, vender o exponer a la venta, distribuir, publicar
o difundir, por cualquier medio - incluso por medio de comunicación masivo
o sistema de informática o telemática -, fotografía, video u otro registro [Received/Recebido: Julho 18, 2018; Accepted/Aceito: Junho 06, 2019] 
audiovisual que contenga imágenes de violación o de violación de vulnerable o que haga apología o induzca su practica o, sin el consentimiento de la víctima, imágenes de sexo, desnudez o pornografía: Pena - reclusión, de 1 (un) a 5 (cinco) años, si el hecho no constituye crimen más grave. Aumento de pena. Párrafo 10 La pena es aumentada en 1/3 (un tercio) a 2/3 (dos tercios) si el crimen es practicado por agente que mantiene o haya mantenido relación íntima de afecto con la víctima o con la finalidad de venganza o humillación. Exclusión de ilicitud. Párrafo $2^{\circ}$ No hay crimen cuando el agente practica las conductas descritas en el caput de este artículo en publicación de naturaleza periodística, científica, cultural o académica con la adopción de medio que imposibilite la identificación de la víctima, resguardada su previa autorización, caso sea mayor de 18 (dieciocho) años (BRASIL, 2018).

La pornografía de venganza estaría incluida en la conducta de difusión de imágenes de sexo o desnudez y, más específicamente, en la causa de aumento de pena del párrafo primero. Como el tipo hace mención a otras situaciones distintas de la pornografía de venganza - difusión de imágenes de violación y de violación de vulnerable y de pornografía sin el consentimiento de la víctima - será utilizada la expresión "difusión de imágenes de sexo o desnudez" para referirse al tipo penal respecto a revenge porn, aunque el nombre del tipo en su totalidad sea "Difusión de imágenes de violación o de imágenes de violación de vulnerable, imágenes de sexo o de pornografía".

También es relevante apuntar que la terminología "pornografía" no se refiere a la pornografía de venganza, de modo que se dirige a la pornografía propiamente dicha, refiriéndose a la industria pornográfica.

El tipo del artículo 218-C criminaliza la conducta de la difusión de fotos o videos de desnudez o sexo de una persona sin su consentimiento. Tal tipo no trata sobre el modo de obtención de este registro. Así, es posible que el agente que divulgó las fotos haya intercambiado fotos o videos de carácter sexual con la víctima - lo que configura el sexting, conducta permitida por la legislación - o que tenga invadido la computadora de la víctima - lo que configuraría la conducta del artículo 154-A del Código Penal. En ambos casos, sería adecuada la aplicación del tipo penal del artículo 218-C, y en el segundo caso, habría una acumulación con el tipo de invasión de dispositivo informático del artículo 154-A. 
Se verifica que el artículo 218-C, además de criminalizar la pornografía de venganza, también puede ser suscitado en casos de difusión no consentida en general, o sea, en situaciones en las cuales no necesariamente hay la motivación puramente de venganza - la motivación puede ser económica, por ejemplo - o consentimiento en la obtención de las fotos, sin el contexto de un relacionamiento íntimo entre víctima y agresor.

Con la nueva ley, no se criminaliza el almacenamiento de estas fotos o videos de contextos de revenge porn. De esta forma, caso un individuo divulgue una foto de su expareja desnuda en un grupo con múltiples participantes y todos estas personas hayan almacenado la foto, pero no la difundieron a nadie, solamente será punida la persona que las divulgó en primer lugar.

El tipo en cuestión no discrimina ninguna característica específica del sujeto activo para el cometimiento del hecho criminoso. De este modo, cualquier persona que divulgue un registro, foto o video, de sexo o desnudez sin el consentimiento del individuo retratado puede incurrir en este crimen, independiente de relacionamiento anterior con la víctima o no.

El párrafo 2ํㅡㄹ del artículo 218-C presenta una exclusión de ilicitud que se dirige a la difusión de dichos registros para fines académicos, periodísticos, científicos o culturales, desde que se adopte un método que haga imposible la identificación de la víctima. De modo contrario, caso la conducta no siga esta directriz, es posible que se verifique el tipo, incluso por la conducta de periodistas o administradores de páginas web o blogs, cuando es evidente la falta de consentimiento de la víctima.

El legislador hizo la opción de tratar, en el mismo artículo, las conductas de divulgación de imágenes de violación, de violación de vulnerable o de imágenes de sexo o desnudez o pornografía. Tal estructura, además de dificultar la comprensión del tipo, es problemática esencialmente por dos razones.

En primer lugar, al reunir estas conductas bajo el mismo artículo y, por lo tanto, con la misma pena, el ordenamiento jurídico revela una valoración de la conducta de la pornografía de venganza como un comportamiento tan reprochable como el de la difusión de imágenes de violación o de violación de vulnerable. A pesar de que la 
pornografía de venganza es una forma de violencia de género, no es tan grave como la divulgación de imágenes de violación y mucho menos cuando dichas imágenes se tratan de una violación de persona vulnerable, el cual se constituye en un contexto totalmente distinto de revenge porn.

La decisión más adecuada sería la distribución de dichas conductas en dispositivos distintos, ofreciendo una gradación de acuerdo con la reprochabilidad social y respetando la proporcionalidad del tratamiento concedido por el Derecho Penal.

En segundo lugar, hay un problema en reunir crímenes sexuales contra vulnerables y no vulnerables en la misma disposición como fue hecho en el caso del artículo 218-C. Al hacerlo, el legislador optó por insertar este artículo en el Capítulo II - De los Crímenes Sexuales Contra Vulnerables, lo que no proporciona el tratamiento más adecuado para los casos en los cuales la víctima no es una persona vulnerable, también contemplados por el texto del dispositivo.

El legislador, por lo tanto, en vez de otorgar el tratamiento más compatible y adecuado al tema según el bien jurídico ofendido por la pornografía de venganza, acabó por añadir dicha conducta en el capítulo de crímenes sexuales contra vulnerables.

El tipo penal en cuestión fue inserido en el Título VI del Código Penal, que abarca los delitos violadores de la dignidad sexual. En este ámbito, el legislador fue adecuado en su elección, puesto que la pornografía de venganza es conducta que ofende al bien jurídico de la dignidad sexual. Sin embargo, se equivocó en lo que consideró la conducta bajo la perspectiva de los crímenes sexuales contra vulnerables, mientras que podría haber puesto dicho tipo penal en el capítulo de los crímenes contra la libertad sexual. La libertad sexual es un aspecto de la dignidad sexual y también es en bien jurídico ofendido por la pornografía de venganza, como se expuso en el tópico anterior.

Por lo tanto, respecto al aspecto estructural del artículo 218-C, el legislador debería haber conferido más clareza, adecuación y especialidad a la inserción del referido tipo penal en el Código, de modo a tutelar de forma suficiente no solamente 
la conducta de la pornografía de venganza, pero también estas otras conductas, que evidentemente se tratan de comportamientos más reprochables socialmente.

Según el Derecho Penal brasileño, el artículo 218-C se trata de un tipo mixto alternativo, ya que describe una pluralidad de conductas fungibles. No hace falta que el individuo haya vendido, publicado y/o divulgado fotografía, video u otro registro audiovisual, puesto que su conducta corresponde al cometimiento de un único delito.

Respecto a la naturaleza de violencia de género, el tipo penal no menciona que la conducta se dirija hacia una mujer o no. Aún así, se verifica que hay una clara mención a la pornografía de venganza en el párrafo $1^{\circ}$ del artículo 218-C, que establece la causa de aumento de pena "si el crimen es practicado por agente que mantenga o haya mantenido relación íntima de afecto con la víctima o con la finalidad de venganza o humillación" (BRASIL, 2018).

Como fue expuesto en este estudio, la pornografía de venganza es una violencia de género, de modo que raramente hay humillación disociada de la concepción social involucrada en el contexto de la sexualidad femenina. Por lo tanto, aunque sea posible una venganza por medio de la difusión de fotos o videos de desnudez masculina, esta situación es la más común. Además, cuando este esta conducta atinge el hombre, sus consecuencias son menos graves que para las mujeres.

La nueva legislación eligió proteger hombres y mujeres de igual modo, pero describiendo una conducta que afecta mucho más al género femenino. Pese a las condiciones de vulnerabilidad de la mujeres en relación al hombre, bien como la razón del grado de lesividad de la exposición íntima femenina, es posible que se recurra a los mecanismos de protección estipulados por la Ley Maria da Penha, conforme se verá adelante.

Por fin, la Ley 13.718/2018 modificó la especie de acción penal de los crímenes sexuales. Antes de la nueva previsión legal, los crímenes sexuales se procesaban a través de acción penal pública condicionada. Tal dispositivo es el más adecuado para estos casos ya que pone en el mismo estándar el interés público de punir crímenes de alta reprochabilidad social y los intereses individuales de las 
víctimas en optar por la persecución penal o no. Entretanto, con la alteración legal, los crímenes sexuales se procesarán por medio de acción penal pública incondicionada, lo que significa que la manifestación de interés de la victima en la persecución penal no es necesaria para que tales violaciones se procesen criminalmente, bastando la iniciativa del órgano acusatorio.

\section{LA APLICABILIDAD DE LA LEY MARIA DA PENHA EN CASOS DE PORNOGRAFÍA DE VENGANZA}

La Ley 11.340/06, conocida como Ley Maria da Penha, fue creada con el objetivo de proteger el artículo 226, párrafo $8^{\circ}$ de la Constitución Federal ${ }^{6}{ }^{7}$, así como diversos dispositivos internacionales ratificados por Brasil que tienen por objetivo la tutela de los Derechos de la Mujer, como la Convención sobre la Eliminación de Todas las Formas de Discriminación contra las Mujeres (BRASIL, 2002), llamada simplemente de Convención de la Mujer, y la Convención Interamericana para Prevenir, Punir y Erradicar la Violencia contra la Mujer, conocida como la Convención de Belém do Pará (LIMA, 2016, p.897).

La Ley Maria da Penha no presenta tipos penales específicos ${ }^{8}$, de modo que no hace mención a la pornografía de venganza. Sin embargo, tal hecho no impide que este delito sea analizado en el marco de dicha ley, especialmente ya que esta ley dispone de un sistema de protección contra la violencia doméstica contra la mujer.

\footnotetext{
${ }^{6}$ El artículo 226, párrafo $8^{\circ}$ de la Constitución Federal trata sobre la asistencia familiar en la persona de cada uno de sus integrantes, de modo que el Estado es responsable por elaborar mecanismos para combatir la violencia en este ámbito.

${ }^{7}$ Pensamos que no es posible afirmar que la Ley 11.340/2006 cumple un mandato constitucional de criminalización originario del citado artículo 226, párrafo $8^{\circ}$, ya que dicha norma, salvo el recién añadido artículo 24-A (incluido por la Ley 13.641/2018, que trata sobre la criminalización del incumplimiento de medida de protección) no posee el objetivo de presentar un rol de criminalización de conductas, sino que de presentar mecanismos para cohibir la violencia doméstica y familiar contra la mujer, aplicados a los delitos ya descritos en el Código Penal brasileño y leyes.

8 Excepto el artículo 24-A, añadido por la Ley 13.641/2018, que trata de la criminalización del incumplimiento de medida de protección.
} 
Es necesario observar, en este sentido, los requisitos para que esta ley sea aplicada en el caso concreto, con el recorte específico que trae y a los fines a los cuales se destina. El objetivo de la Ley Maria da Penha es cohibir la violencia doméstica y familiar practicada contra la mujer, compensando desigualdades históricas entre los géneros masculino y femenino, promoviendo la isonomía constitucional entre hombres y mujeres. En los artículos $2^{\circ}$ y $3^{\circ}$ de la Ley 11.340/06 son relacionados los derechos y garantías fundamentales específicamente asegurados a la mujer:

\begin{abstract}
Artículo $2^{\circ}$ Toda mujer, independientemente de su clase, raza, origen étnico, orientación sexual, ingresos, cultura, nivel educativo, edad y religión, disfruta de los derechos fundamentales inherentes a la persona humana, y se le brindan las oportunidades y facilidades para vivir sin violencia. preservar su salud física y mental y su mejora moral, intelectual y social. Artículo $3^{\circ} \mathrm{Se}$ garantizará a las mujeres las condiciones para el ejercicio efectivo de sus derechos a la vida, seguridad, salud, alimentación, educación, cultura, vivienda, acceso a la justicia, deporte, ocio, trabajo, ciudadanía, libertad, dignidad, respeto y vida familiar y comunitaria. Párrafo $1^{\circ}$ El poder público desarrollará políticas destinadas a garantizar los derechos humanos de las mujeres en el contexto de las relaciones domésticas y familiares para protegerlas de toda forma de abandono, discriminación, explotación, violencia, crueldad y opresión. Párrafo $2^{\circ}$ Corresponde a la familia, la sociedad y el poder público crear las condiciones necesarias para el ejercicio efectivo de los derechos establecidos en el caput (BRASIL, 2006).
\end{abstract}

Los objetivos establecidos en la Ley Maria da Penha corresponden perfectamente con la conducta que se desea cohibir de la pornografía de venganza. La Ley evidencia que garantiza el derecho a la libre determinación y la libertad, enfatizando la importancia de una vida familiar y comunitaria saludable para las mujeres, situaciones que son imposibilitadas por la práctica en cuestión.

La aplicación de la Ley 11.340 / 06 en casos concretos está sujeta a tres supuestos o requisitos (LIMA, 2016, p.902): el sujeto pasivo mujer ${ }^{9}$, la práctica de violencia en los casos previstos en el artículo $7^{\circ}$ y la violencia dolosa practicada, alternativamente (y no acumuladamente), en el ámbito de la unidad doméstica, de la

\footnotetext{
${ }^{9}$ No es objeto de esta investigación la análisis de la aplicabilidad de la Ley Maria da Penha en violencia contra personas transgénero, por esto no se profundizará mucho en este requisito.
} 
familia o en cualquier relación íntima de afecto, situaciones en las cuales se presume más vulnerabilidad femenina.

En primer lugar, es notable que la necesidad de un sujeto pasivo mujer para la configuración de la Ley Maria da Penha imposibilita casos de pornografía de venganza que sean tutelados según esta ley cuyas víctimas son hombres. La pornografía de venganza afecta más las mujeres que los hombres, sea cuantitativamente, en numero de víctimas, sea cualitativamente, en los daños causados a las víctimas del género femenino, cuyas consecuencias son más graves que para los hombres.

En este sentido, aplicar la Ley Mari da Penha a la conducta estudiada protegería la mayoría de los casos de revenge porn. Para los casos con víctimas hombres, entretanto, la persecución penal se daría de modo totalmente distinto, ya que la Ley 11.340/06 establece un sistema completo de procedimientos, medidas e instancias especiales, como los Juzgados de Violencia Doméstica y Familiar contra la Mujer, medidas de protección de urgencias específicas, etc.

Cuanto a la necesidad de la practica de violencia física, psicológica, sexual, patrimonial o moral para la aplicación de dicha ley, en la pornografía de venganza este requisitio se cumple ya que se trata de una violencia de carácter psicológico que se desarrolla con la difusión no consentida del material íntimo. En este sentido:

\begin{abstract}
Art. 70 São formas de violência doméstica e familiar contra a mulher, entre outras: II - a violência psicológica, entendida como qualquer conduta que lhe cause dano emocional e diminuição da auto-estima ou que lhe prejudique e perturbe o pleno desenvolvimento ou que vise degradar ou controlar suas ações, comportamentos, crenças e decisões, mediante ameaça, constrangimento, humilhação, manipulação, isolamento, vigilância constante, perseguição contumaz, insulto, chantagem, ridicularização, exploração e limitação do direito de ir e vir ou qualquer outro meio que lhe cause prejuízo à saúde psicológica e à autodeterminação (BRASIL, 2006).
\end{abstract}

Não há dúvidas quanto à natureza psicológica da violência da pornografia de vingança. Esta atinge todos os campos da vida da vítima em um nível psíquico, alterando suas relações interpessoais, seu desenvolvimento e até mesmo suas crenças. A violência da pornografia de vingança não poderia ser considerada moral, 
assim tida pela Lei 11.340/06 como "qualquer conduta que configure calúnia, difamação ou injúria", com o melhor entendimento de que a pornografia de vingança não se trata meramente de um crime contra a honra, como defendido em tópico anterior.

A necessidade da violência ocorrer no âmbito da unidade doméstica, da família ou de qualquer relação íntima de afeto revela-se em outra situação em que a Lei Maria da Penha limita sua aplicação a determinados casos da pornografia de vingança. $\mathrm{O}$ entendimento que se dá para o âmbito da unidade doméstica ou âmbito da família segundo a Lei 11.340/06 é amplo. Assim sendo:

\begin{abstract}
Artículo 5 Para los propósitos de esta Ley, la violencia doméstica y familiar contra las mujeres constituirá cualquier acción u omisión basada en el género que cause su muerte, lesiones, sufrimiento físico, sexual o psicológico y daño moral o de propiedad: I - en el ámbito de la unidad doméstica, entendida como el espacio para la convivencia permanente de las personas, con o sin lazos familiares, incluidos los agregados esporádicamente; II - en el ámbito de la familia, entendida como la comunidad formada por individuos que están o se consideran relacionados, unidos por lazos naturales, afinidad o voluntad expresa; III - en cualquier relación íntima de afecto, en la que el agresor vive o ha vivido con la ofendida, independientemente de la coabitación. Párrafo único. Las relaciones personales enumeradas en este artículo son independientes de la orientación sexual.
\end{abstract}

La Ley Maria da Penha, sin dudas, tutela la violencia de la pornografía de venganza, si la relación entre la víctima y el autor se encuentra descrita en los incisos I, II o III del artículo 5 de dicha Ley.

El inciso III del artículo $5^{\circ}$ amplia mucho las posibilidades de aplicación de tal ley en casos de pornografía de venganza, ya que establece que la violencia doméstica y familiar puede pasar en el ámbito de "cualquier relación íntima de afecto". Por lo tanto, se incluyen en este inciso otros relacionamientos distintos de matrimonios y uniones de hecho, como relacionamientos más casuales, compromisos, etc, dependiendo del caso concreto.

Concluyendo, la Ley Maria da Penha es aplicable para tutelar casos de pornografía de venganza, no solamente debido al hecho de que este fenómeno es una manifestación de la violencia de género, pero también a causa de que los casos 
de ocurrencia de la pornografía de venganza se adecuan perfectamente en el recorte de la Ley Maria da Penha.

\section{CONCLUSÃO}

Uno de los puntos clave del trabajo es unir el conocimiento sociológico al conocimiento legal, para producir conocimiento que, aunque específico, puesto que elaborado dentro de la delimitación del tema, sea capaz de combinar informaciones, percepciones y nociones diferentes para que sea posible una confrontación completa de la cuestión. De este modo, evidentemente, se justifica el uso de elementos, discusiones y teóricos de la sociología para el derecho. El área legal se complementa con el conocimiento de la sociología, ya que la ley existe solo para servir como instrumento para el pleno desarrollo de la sociedad.

La pornografía de venganza deja marcas profundas en la sociedad. Es el objetivo de esta investigación verificar si se podría caracterizar dicha práctica como violencia de género. A partir del análisis de dispositivos del Derecho Internacional e interno, así como del modo como esta practica sucede, se visualiza que la pornografía de venganza no podría ser considerada otra cosa que no una forma de violencia de género.

Otro objetivo es averiguar si la pornografía de venganza podría ser adecuadamente tratada como un crimen contra la honra, como se ha estado tutelando esta conducta. Con la modificación legislativa de la Ley 13.718/18 y la creación de un tipo penal específico, el Derecho Penal se adecuó a la realidad y tuteló un bien jurídico que antes no disponía de protección específica en circunstancias de revenge porn. Después de toda la investigación, se constató que el fenómeno de la pornografía de venganza no puede ser considerado solamente como un crimen contra la honra y su tratamiento como tal es inadecuado e insuficiente. Respecto al análisis de la aplicabilidad de la Ley Maria da Penha para casos de pornografía de venganza, se 
verifica que los resultados fueron positivos en el sentido de ser posible la aplicación de esta ley para mayor protección de las mujeres víctimas de este crimen.

El presente estudio no tiene la pretensión de agotar el tema, de modo que lo que desea es justamente visibilizar esta importante discusión y estimular la reflexión en busca de soluciones que puedan alterar algunas construcciones sociales. Utilizar el Derecho Penal en sí mismo, como modo de tranquilizar o de acabar con una sensación de inseguridad y desprotección del bien jurídico, contribuye a la violencia, así como para el mantenimiento de un orden patriarcal. Hay que aceptar que en la expresión de sexualidad de forma consentida no hay ningún equívoco, pero exponer la intimidad de otras personas, si. En el contexto de la víctima mujer, se trata de una violencia de género originaria de la reproducción del machismo, que ocurre de diversas formas, pero, en este caso, como una manifestación de la modernidad.

La discusión sobre la pornografía de venganza debe ser incentivada en cualquier ámbito. Hay que tener en cuenta que la pornografía de venganza, sin el juicio por parte de la sociedad, no sería un fenómeno tan granda tal cual es. Consecuentemente, no sólo es necesario discutir modos de enfrentar la práctica judicialmente, pero también es de gran importancia - y complementar a la actividad del Poder Judiciario - hacer que la sociedad comprenda el fenómeno. Las conquistas vienen por el esfuerzo dialéctico de cada ciudadano.

\section{REFERÊNCIAS}

ALMEIDA, Mariana Nogueira de. A pornografia não consensual como delito do direito penal informático, sua aplicação no direito brasileiro e a análise da mulher como principal vítima. 2015. 84 f. TCC (Grado) - Curso de Derecho, Universidad Federal de Rio Grande do Sul, Porto Alegre, 2015.

BEAUVOIR, Simone de. O Segundo Sexo: A experiência vivida. 2. ed. São Paulo: Difusão Europeia do Livro, 1967. Livro, 1970.

O Segundo Sexo: fatos e mitos. 4. ed. São Paulo: Difusão Europeia do 
BRASIL. Decreto no 4.377, de 13 de septiembre de 2002. Convenção sobre a Eliminação de Todas as Formas de Discriminação contra a Mulher. Disponible en: <http://www.planalto.gov.br/ccivil_03/decreto/2002/d4377.htm>.

Decreto-ley no 2.848, de 07 de enero de 1940. Código Penal. Rio de Janeiro, RJ. Disponible en: http://www.planalto.gov.br/ccivil_03/decretolei/Del2848compilado.htm

Disponible en:

Ley no 11.340, de 07 de agosto de 2006. Brasilia, DF, 07 ago. 2006. 2006/2006/lei/11340.htm http://www.planalto.gov.br/ccivil_03/_ato2004-

Ley no 13.718, de 24 de septiembre de 2018. Brasilia, DF, Disponible en: <http://www.planalto.gov.br/ccivil_03/_Ato2015-2018/2018/Lei/L13718.htm>.

CIDH - Comisión Interamericana de Derechos Humanos. Convención Interamericana para Prevenir, Punir y Erradicar la Violencia contra la Mulher "Convención de Belém do Pará". Belém do Pará, 1994. Disponible en: <http://www.cidh.org/Basicos/Portugues/m.Belem.do.Para.htm>

EXTRA. Ex-bbb jonas sulzbach diz que vídeo íntimo o persegue: 'tudo que eu posto vira 22. 2016. In: Globo. Disponible en: <https://extra.globo.com/famosos/ex-bbbjonas-sulzbach-diz-que-video-intimo-persegue-tudo-que-eu-posto-vira-2219176405.html>. Acceso en: 27 julio 2017..

FELDENS, Luciano. A Constituição penal: a dupla face da proporcionalidade no controle das normas penais. Porto Alegre: Livraria do advogado, 2005.

LIMA, Renato Brasileiro de. Legislação Criminal Especial Comentada. 4. ed. Salvador: Juspodivm, 2016.

VALENTE, Mariana Giorgetti; NERIS, Natália; RUIZ, Juliana Pacetta; BULGARELLI, Lucas. O Corpo é o Código: estratégias jurídicas de enfrentamento ao revenge porn no Brasil. InternetLab: São Paulo, 2016.

NOMURA, Leandro. 'Crime na internet é ferida aberta', diz mãe sobre fotos nuas vazadas pelo ex. Folha de S. Paulo. São Paulo, p. 1-1. 21 mayo 2017. Disponível em: <http://www1.folha.uol.com.br/empreendedorsocial/minhahistoria/2017/05/1885458crime-na-internet-e-ferida-aberta-diz-mae-sobre-fotos-nuas-vazadas-pelo-ex.shtml> .

NUCCI, Guilherme de Souza. Manual de Direito Penal. 12. ed. Rio de Janeiro: Forense, 2016. 
OLIVEIRA, Glaucia Fontes de. Violência de gênero e a lei Maria da Penha. Conteúdo Jurídico, Brasilia-DF: 06 octubre 2010. Disponible en: <http://www.conteudojuridico.com.br/?artigos\&ver=2.29209.

ONU - Organización de las Naciones Unidas. Declaración sobre la eliminación de la violencia contra la mujer. Nova York, 1993. Disponible en: < https://www.ohchr.org/sp/professionalinterest/pages/violenceagainstwomen.aspx >. Acceso en: 30 julio 2017.

PERROT, Michelle. Minha história das mulheres. São Paulo: Contexto, 2007.

SAFERNET. Indicadores

<http://helpline.org.br/indicadores/>.

<http://www.safernet.org.br/site/institucional>.

SARLET, Ingo Wolfgang; MARINONI, Luiz Guilherme; MITIDIERO, Daniel. Curso de Direito Constitucional. 6. ed. São Paulo: Saraiva, 2017.

SCOTT, Joan Wallach. Gênero: uma categoria útil de análise histórica. Educação \& Realidade. Porto Alegre, vol. 20, n. 2, jul./dic. 1995, p. 71-99. Disponible en: https://edisciplinas.usp.br/pluginfile.php/1840746/mod_resource/content/0/G\%C3\%A Anero-Joan\%20Scott.pdf.

VALENTE, Mariana; NERIS, Natália; KIRA, Beatriz. Análise: Projeto que criminaliza envio de 'nudes' no Brasil aponta para retrocessos. 2017. Disponible en: $<$ http://link.estadao.com.br/noticias/cultura-digital,analise-projeto-que-criminalizaenvio-de-nudes-no-brasil-aponta-para-retrocessos,70001677611>. 